ORIGINAL ARTICLE

\title{
Injuries in women's professional soccer
}

\author{
E Giza, K Mithöfer, L Farrell, B Zarins, T Gill
}

Br J Sports Med 2005;39:212-216. doi: 10.1136/bjsm.2004.011973

See end of article for authors' affiliations ......................

Correspondence to: Dr Eric Giza, Central Maine Orthopaedics, 690 Minot Ave, Suite One, Auburn, ME 04210, USA; egiz@massmed.org

Accepted 15 June 2004

\begin{abstract}
Objective: The injury data from the first two seasons of the Women's United Soccer Association (WUSA) were analysed to determine the injury incidence, anatomic location of injuries, and relation of player position.

Methods: Injury data on 202 players from eight teams during the first two seasons of the WUSA were prospectively collected and analysed.

Results: A total of 173 injuries occurred in 110 players with an overall injury incidence rate of 1.93 injuries per 1000 player hours. The incidence of injury during practice and games was 1.17 and 12.63 per 1000 player hours, respectively. Of the injuries $82 \%$ were acute and $16 \%$ were chronic. Most of the injuries $(60 \%)$ were located in the lower extremities. Strains $(30.7 \%)$, sprains (19.1\%), contusions (16.2\%), and fractures $(11.6 \%)$ were the most common diagnoses and the knee $(31.8 \%)$ and head $(10.9 \%)$ were the most common sites of injury. Anterior cruciate ligament $(A C L)$ injuries accounted for $4.6 \%$ of all injuries and the incidence of ACL tears was 0.09 per 1000 player hours (practice 0.04, game 0.90). Midfielders suffered the most injuries $(p<0.007)$.

Conclusion: We conclude that the injury incidence in the WUSA is lower than the 6.2 injuries per 1000 player hours found in the corresponding male professional league (Major League Soccer); however, knee injuries predominate even in these elite female athletes.
\end{abstract}

S occer is the world's most popular organised sport with over 200 million males and 21 million females registered with the Fèdèration Internationale de Football Association (FIFA). Epidemiological studies of male soccer players have identified an incidence of 10-35 injuries per 1000 game hours, equivalent to every player incurring one performance limiting injury per year. ${ }^{1-3}$ A review of the English professional male soccer leagues revealed that muscle strains (37\%), ligament sprains (19\%), and contusions (13\%) were the most common types of injury, and that the thigh $(23 \%)$, knee $(17 \%)$, and ankle $(17 \%)$ were the most common sites of injury. ${ }^{4}$ Studies on professional and amateur female soccer players in Sweden have demonstrated an incidence of up to 24 injuries per 1000 game hours and up to seven injuries per 1000 practice hours. ${ }^{5-7}$

Several studies have identified female soccer players as having a higher incidence of knee injury and anterior cruciate ligament (ACL) injury than males. ${ }^{8-11}$ In a prospective study of female soccer players, Östenberg and colleagues determined that general joint laxity and age over 25 are risk factors for knee injury; however, no study has proven that a single etiology is responsible for female ACL injury patterns. ${ }^{512}$

In the United States 12.5-18.5 million people play soccer, with an estimated annual increase in participation of up to $21.8 \% .^{13}$ The growing popularity of soccer in the United States has led to the recent formation of professional male (1996) and female soccer leagues (2001). The first women's World Cup soccer tournament was held in 1991 and the Women's United Soccer Association (WUSA) was the premier female soccer league in the world from 2001 to 2003. The interest of female athletes in soccer necessitates continued investigation of injuries in order to identify injury patterns and effective means of prevention. ${ }^{14}$ The injury data from the first two seasons of the WUSA were analysed to determine the injury incidence, anatomic location of injuries, and relation of player position.

\section{METHODS}

Injuries in this study were defined as those conditions which were reported to and evaluated by the team physician or athletic trainer. Each injury was subsequently reported to the league insurance company via a standardised "first report of injury" form which is completed by the team trainer. All injury reports were verified by an examination by the team physician. A detailed account of each injury is recorded in a general computer database and includes the date of injury, injury location, diagnosis, injury description, and reimbursement cost.

For this investigation, the information in the database from all eight teams during the 2001 and 2002 pre-season, season, and post-season was carefully reviewed and each team trainer was contacted for further injury detail. Each player signed a release of medical records form as part of their WUSA contract. A numerical code was assigned to each player to protect confidentiality and permission for the use of the information was granted by the WUSA administration (Atlanta, GA) and American Specialty Insurance Services, Inc. (Roanoke, IN).

Injury onset was determined by the detailed injury description, if available. An acute injury was defined as any injury or condition which had not existed prior to the date of injury occurrence. A chronic injury was any injury with insidious progression that existed prior to the date of injury occurrence or an exacerbation of a previously existing condition.

The average number of practices per season (125 sessions, average time $100 \mathrm{~min}$ ) as recorded by team trainers and the average number of games per season ( 21 games, average time $90 \mathrm{~min}$ ) for all teams was used to calculate the injury incidence using the method described by Hawkins and

Abbreviations: $\mathrm{ACL}$, anterior cruciate ligament; FIFA, Fèdèration Internationale de Football Association; MLS, Major League Soccer; WUSA, Women's United Soccer Association 
Fuller. ${ }^{15}$ The season runs from mid-February until August with additional post-season play. The season was divided into pre-season (mid-February through March), early season (April through May 15th), midseason (May 16th through June), late season (July through end of season games in midAugust), and post-season. All calculations were performed using Microsoft Excel (Microsoft, Seattle, WA) and Statistica (Statsoft, Tulsa, OK) $\chi^{2}$ Statistical tests were used to analyse the data, with significance accepted at $\mathrm{p}<0.05$ unless otherwise indicated.

\section{RESULTS}

\section{Injury incidence}

A total of 173 injuries occurred over two seasons: 93 injuries occurred during 2001 and 80 occurred during 2002. Of 202 players participating in the WUSA during the two seasons, 110 suffered injuries; therefore $55 \%$ of players were injured. The overall injury incidence rate was 1.93 injuries per 1000 player hours. Game versus practice information was available for 168 injuries, and the game and practice injury incidences per 1000 player hours were 12.63 and 1.17 , respectively.

\section{Injury type and location}

Injury type is summarised in fig 1 and injury location in fig 2 . Strains $(30.7 \%)$, sprains $(19.1 \%)$, contusions $(16.2 \%)$, and fractures $(11.6 \%)$ were the most common diagnoses. The most common location was the knee $(31.8 \%)$, followed by the head $(10.4 \%)$, ankle $(9.3 \%)$, and foot $(9.3 \%) ; 60 \%$ of the injuries occurred in the lower extremities. Of the injuries $82 \%$ were acute (142), 16\% were chronic (28), $0.6 \%$ were acute on chronic (one), and $1.4 \%$ were undetermined (two).

Of 18 head injuries, fractures of the nose and facial bones (five, $27.8 \%$ ) and concussions (five, 27.8\%) occurred most frequently. The remainder of the head injuries were lacerations and contusions. The incidence of concussions was 0.06 per 1000 player hours.

Ankle sprains accounted for $86.7 \%$ of ankle injuries and $7.51 \%$ (13) of all injuries. Eight of 13 ankle sprains involved a plantarflexion/inversion mechanism.

Of 20 fractures, the face and teeth (six, 30\%) and the foot (five, 25\%) were the most frequent sites of injury. Stress fractures (one tibia, one first metatarsal) accounted for two fractures $(10 \%)$ and the remaining 18 were the result of acute situations

\section{Knee injuries}

A total of 55 knee injuries occurred. Strains were the most common injury $(15,27.3 \%)$ followed by contusions (nine, $16.4 \%$ ), ACL injury (eight, 14.6\%), sprains not involving the ACL (seven, 12.7\%), inflammation (seven, 12.7\%), and meniscal tear (five, 9.1\%). Follow up investigation on the diagnosis of knee ligament sprain was performed to determine if an ACL injury had occurred. There were eight acute ACL tears during the two seasons, five from games and three from practices. Six of the eight were the result of noncontact situations, two were from collisions, and one was associated with a meniscal tear. The incidence of ACL tear was 0.09 per 1000 player hours. ACL tear rates during games and practice were 0.90 and 0.04 , respectively, per 1000 player hours.

\section{Injury and time of season}

The distribution of all injuries is shown in fig 3. Significantly more injuries occurred during the latter portion of the competitive season $(p<0.018)$ and less occurred during the post season $(\mathrm{p}<0.005)$.

\section{Player position}

Player position at the time of injury was recorded for 168 players. Midfielders sustained the most injuries (57, 34.1\%) followed by defenders $(47,28.1 \%)$, strikers $(38,22.8 \%)$, and goalkeepers $(26,15.0 \%)$. Compared to all players, midfielders suffered a significantly higher number of injuries $(p<0.007)$; however, compared to other field players, midfielder injuries did not reach a significant value.

\section{DISCUSSION}

The overall incidence of injury in this study was 1.93 injuries per 1000 player hours. The game incidence was 12.63 and the practice incidence was 1.17. Our findings are consistent with both the practice injury rates (range $1.5-7$ per 1000 player hours) and the game injury incidence (range 9.1-24 per 1000 player hours) found in other female soccer studies. ${ }^{5-7}$ Higher game injury rates have also been found in male soccer and have been attributed to greater intensity of play during games. ${ }^{4} 1617$

Morgan and Oberlander investigated the injuries of the inaugural season of Major League Soccer (MLS) and found an overall injury rate of 6.2 injuries per 1000 player hours. ${ }^{1}$ In accordance with their method study, we included all injuries,

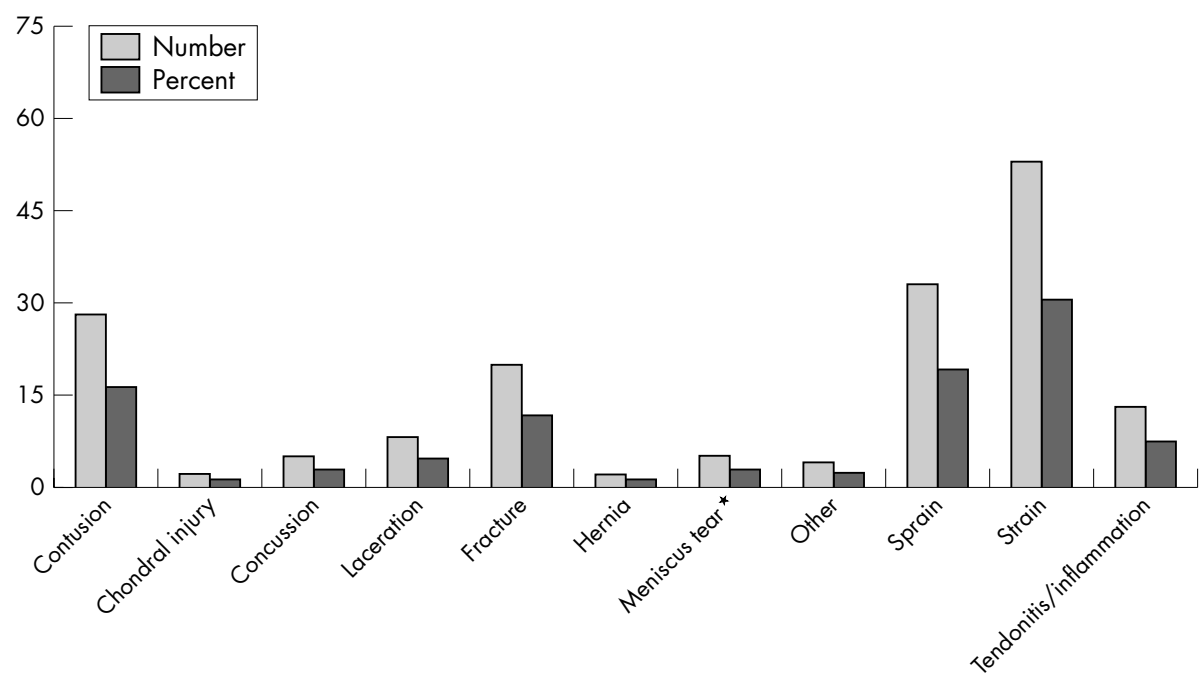

Figure 1 Description of injury. There were five isolated meniscal tears. Another tear was associated with an ACL injury and was grouped with sprains. 


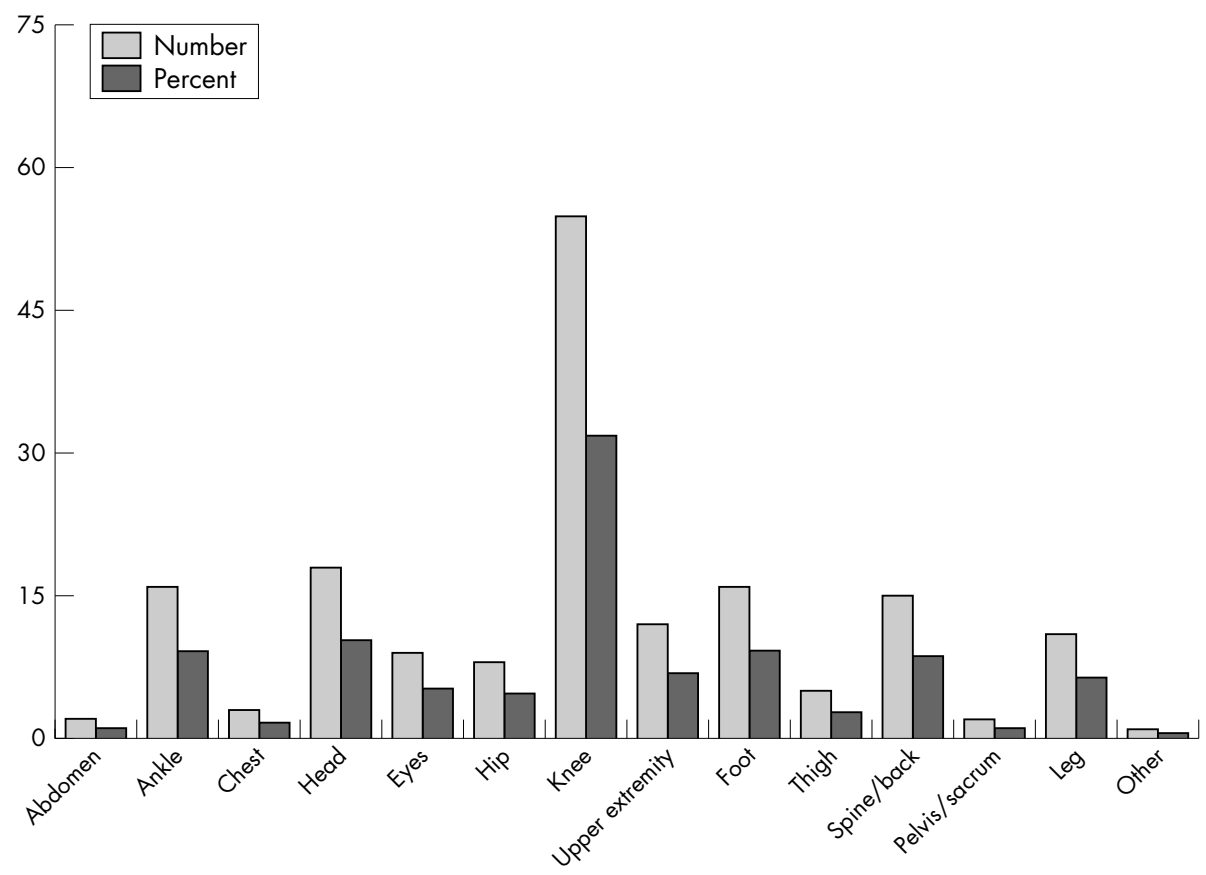

Figure 2 Location of Injury location.

such as upper extremity and facial injuries, and not just those which resulted in time lost from play. Our finding of 1.93 injuries per $1000 \mathrm{~h}$ in the WUSA is important as it may indicate that professional female soccer players in the United States suffer less injuries than their male counterparts.

Although soccer epidemiology studies in the 1970s and early $1980 \mathrm{~s}^{18}{ }^{19}$ showed that females had a higher injury rate, age and skill level may have more of an influence on injury incidence than gender alone. In a 5 day invitational tournament in 1985 with over 6000 players, Schmidt-Olsen et al found that females aged 17-19 had a much higher injury rate (47.1 per $1000 \mathrm{~h}$ ) compared to males in the same age group (20.6 per $1000 \mathrm{~h}) .{ }^{20}$ In 1984, Maehlum et al studied injuries at the Norway Cup, one of the world's largest youth club tournaments, and found the injury rate to be twice as high in females as in males. ${ }^{21}$ In 1999, Maehlum et al compared values from the 1984 tournament to the 1993 and 1997

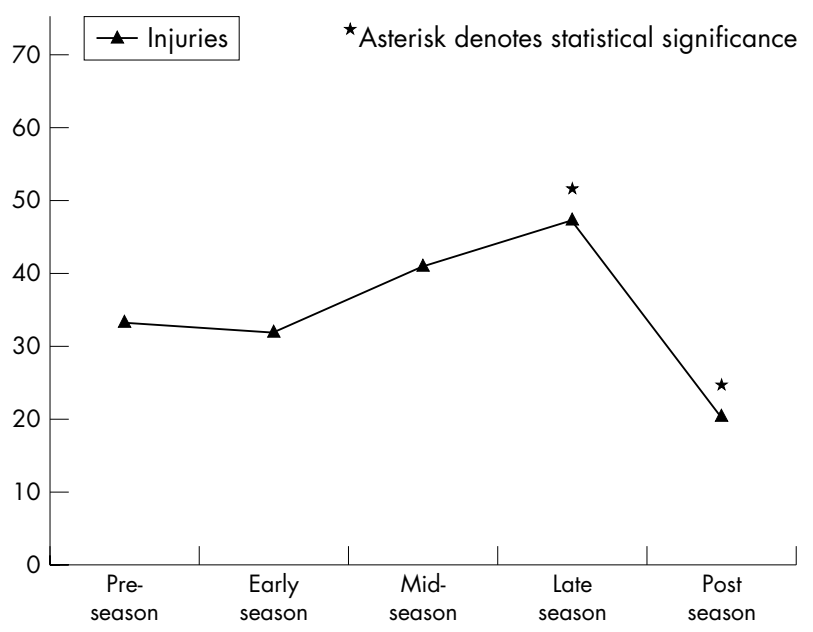

Figure 3 Relationship of time of season with injury occurrence. tournaments, and found a 35\% total decrease in total injuries with a $50 \%$ reduction in female injuries..$^{22}$ Elias identified a gradual decrease in the incidence of injuries in female soccer players from 1987 to 1997 in a recent study in which injuries from a youth soccer tournament were recorded prospectively over 10 years. ${ }^{23}$ Data from the 1999-2000 NCAA injury surveillance system revealed a nearly equal game injury rate in males (20.75 per 1000 player exposures) and females (18.75 per 1000 player exposures $)^{24} 25$; therefore, improved training, fitness, and skills may contribute to the low incidence found in this investigation.

Five concussions occurred during the two seasons (approximately one concussion every 15.3 weeks) and all five situations involved player to player collisions. Boden et al determined the incidence of concussion in female collegiate soccer players to be 0.44 per 1000 athlete exposures, that is approximately one concussion every 13.5 weeks or one concussion per team per year. ${ }^{26}$ Boden et al also found that $76 \%$ of concussions resulted from player to player or player to object (goal post, elbow, sideline advertisement) contact and only $24 \%$ resulted from head to ball contact from a ball kicked at full force at a close range. ${ }^{26}$ The relationship of chronic traumatic brain injury and soccer remains a controversial topic, as Tysvaer and Matser et al have shown in separate studies that soccer players exhibit deficiencies in memory and planning compared to controls..$^{27}$ In contrast, a recent study used similar neuropsychological tests to those used by Matser et al, and showed that soccer related concussions were not associated with impaired neurocognitive function. ${ }^{29}$ Jordan and colleagues compared 20 national soccer team members to controls and found no differences in brain MRI findings. ${ }^{30}$

The finding of an increased number of injuries during the late season is consistent with other studies of both male and female soccer injuries. ${ }^{431}$ The increase in injuries during the end of the season could be due to deconditioning or an increase in play intensity for play-off or tournament positions. The lower incidence in post-season play is expected as fewer players participate. 


\section{What is already known on this topic}

Information on professional female players is limited, and studies on amateur and youth females have identified practice and game injury rates of 1.5-7 and 9.1-24 per 1000 player hours, respectively. Female soccer players have a four times higher risk of knee and $\mathrm{ACL}$ injury than males.

The knee was the most common injury site in our study $(31.8 \%)$, and this finding is consistent with the study of female soccer players by Östenberg et al. ${ }^{5}$ An awareness of the propensity of knee injuries in female soccer players is particularly important for the team physician and team trainer, as it has been shown that 12 years post-injury, 34\% of previous female soccer players in Sweden who suffered an ACL injury have radiographic changes consistent with osteoarthritis. ${ }^{32}$

An overall incidence of 0.09 ACL injuries per 1000 player hours was found in this study. Five of the eight ACL injuries occurred during games (0.90 ACL injures per 1000 game hours). Bjordal and colleagues found an incidence of 0.10 per $1000 \mathrm{~h}$, and other investigators found 0.31 ACL injuries per 1000 h. $^{53}$ Only two of eight ACL injuries involved contact situations, and although the number of ACL injures is too small to reach statistical significance, these results are consistent with published data that a majority of ACL injuries occur in non-contact situations..$^{1033} 34$

Some authors have shown that pre-season neuromuscular training and plyometrics can decrease knee injury rates in females. ${ }^{14} 3536$ Junge and Chomiak have shown a lower injury rate in elite players compared to less skilled players, ${ }^{37}$ and others have shown that pre-season conditioning and fitness can reduce overall injury rates. ${ }^{35} 3839$ The elite soccer players in this study have achieved the highest level of play possible in female soccer; therefore, our findings of a low injury rate could reflect the high level of fitness needed to participate in the WUSA and the impact of proper pre-season strengthening and training. Additionally, our results could represent a "pre-selection" phenomenon in which players who are at risk for an ACL injury may have had an injury earlier in their career and not reached the WUSA or have had an ACL reconstruction procedure prior to their participation in the WUSA.

The use of an insurance database has the limitation of selecting only for those injuries which resulted in an insurance claim. Although all injuries were reviewed by the team trainers and physicians, it is likely that some minor abrasions and contusions were not recorded and may have lowered the injury incidence in this study. Also, the use of a database can not always provide the level of detail for each injury desired for a more comprehensive study. Moreover, the high proportion of fractures and other severe injuries could be due to the selection bias from the type of database utilised.

\section{SUMMARY}

A preliminary study of the injuries among 202 elite female soccer players has shown that the incidence of injury in the WUSA is similar to that found in the existing literature on female soccer injuries, and that rates during game play are much higher than during practice. Injures about the knee are most common and continue to predominate even in these high-level athletes. The results of this study accentuate the importance of a more comprehensive analysis of the injury patterns in these elite athletes to enable the creation of prevention protocols for professional, amateur, and youth female soccer players.
What this study adds

This is the first prospective study of female professional soccer. We have demonstrated that the injury rate in the WUSA is lower than its corresponding male professional league. We have found that the knee is the most common location for injury even in these elite female soccer players.

\section{Authors' affiliations}

E Giza, Central Maine Orthopaedic Group, Auburn, ME, USA

K Mithöfer, Hospital for Special Surgery, New York, NY, USA

L Farrell, Boston Breakers, Boston, MA, USA

B Zarins, T Gill, Massachusetts General Hospital, Boston, MA, USA

Competing interests: none declared

\section{REFERENCES}

1 Morgan B, Oberlander M. An examination of injuries in major league soccer. Am J Sports Med 2001;29:426-30.

2 Hawkins R, Fuller C. A prospective epidemiological study of injuries in four English professional football clubs. Br J Sports Med 1999;33:196-203.

3 Dvorak J, Junge A. Football injuries and physical symptoms. Am J Sports Med 2000;28:S3-9.

4 Hawkins R, Hulse M, Wilkinson C, et al. The Association Football Medical Research Programme: an audit of injuries in professional football. $\mathrm{Br} J$ Sports Med 2001;35:43-7

5 Östenberg A, Roos H. Injury risk factors in female European football. A prospective study of 123 players during one season. Scand J Med Sci Sports 2000; 10:279-85.

6 Soderman K, Adolphson J, Lorentzon R, et al. Injuries in adolescent female players in European football: a prospective study over one outdoor soccer season. Scand J Med Sci Sports 2001;11:299-304.

7 Engstrom B, Johansson C, Tornkvist $\mathrm{H}$. Soccer injuries among elite female players. Am J Sports Med 1991;19:372-5.

8 Arendt E, Dick R. Knee injury patterns among men and women in collegiate basketball and soccer NCAA data and review of literature. Am J Sports Med 1995;23:694-701.

9 Roos H, Ornell M, Gardsell P, et al. Soccer after ACL injury - an incompatible combination? Acta Orthop Scand 1995;66:107-12.

10 Engstrom B, Forssblad M, Johansson C, et al. Does a major knee injury definitely sideline an elite soccer player? Am J Sports Med 1990;18:101-5.

11 Lindenfeld T, Schmitt D, Hendy M, et al. Incidence of injury in indoor soccer. Am J Sports Med 1994;22:364-71.

12 Ireland ML. The female ACL: why is it more prone to injury? Orthop Clin North Am 2002;33:637-51.

13 Anderson S. Injuries in youth soccer: a subject review. Pediatrics 2000;105:659-61

14 Silvers HJ, Mandelbaum BR. Preseason conditioning to prevent soccer injuries in young women. Clin J Sport Med 2001;11:206.

15 Hawkins R, Fuller C. Risk assessment in professional football: an examination of accidents and incidents in the 1994 World Cup Finals. Br J Sports Med 1995;30: 165-70

16 Inklaar H. Soccer injuries I: incidence and severity. Sports Med 1994:18:55-73.

17 Junge A, Chomiak J, Dvorak J. Incidence of football injuries in youth players. Am J Sports Med 2000;28:S47-57

18 Nilsson S, Roaas A. Soccer injuries in adolescents. Am J Sports Med 1978:6:358-61.

19 Maehlum S, Dahl E, Daljord O. Frequency of injuries in a youth soccer tournament. Physician Sports Med 1986;14:73-9.

20 Schmidt-Olsen S, Bunemann LK, Lade V, et al. Soccer injuries of youth. Br J Sports Med 1985;19:161-4.

21 Maehlum S, Daljord OA. Football injuries in Oslo: a one-year study. Br J Sports Med 1984; 18:186-90.

22 Maehlum S, Daljord O, Hansen KJ. Frequency of injuries in youth soccer. Med Sci Sports 1999;31:S401.

23 Elias SR. 10-year trend in USA Cup soccer injuries: 1988-1997. Med Sci Sports Exerc 2001;33:359-67.

24 National Collegiate Athletic Association. Injury surveillance system, women's soccer. Indianapolis, IN: NCAA, 2000.

25 National Collegiate Athletic Association. Injury surveillance system, men's soccer. Indianapolis, IN: NCAA, 2000.

26 Boden B, Kirkendall D, Garrett W. Concussion incidence in elite college soccer players. Am J Sports Med 1998;26:238-41

27 Tysvaer A. Head and neck injuries in soccer. Sports Med 1992;14:200-13.

28 Matser $\mathbf{E}$, Kessels A, Lezak M, et al. Neuropsychological impairment in amateur soccer players. JAMA 1999;282:971-3.

29 Guskiewicz KM, Marshall SW, Broglio SP, et al. No evidence of impaired neurocognitive performance in collegiate soccer players. Am J Sports Med 2002;30: 157-62.

30 Jordan S, Green G, Galanty H, et al. Acute and chronic brain injury in United States National Team soccer players. Am J Sports Med 1996;24:205-10. 
31 Ekstrand J, Hilding J. The incidence and differential diagnosis of acute groin pain in male soccer players. Scand J Med Sci Sports 1999;9:98-103.

32 Lohmander LS, Östenberg A, Englund M, et al. High prevalence of knee osteoarthritis, pain, and functional limitations in female soccer players twelve years after anterior cruciate ligament injury. Arthritis Rheum 2004:50:3145-52.

33 Bjordal JM, Arnly F, Hannestad B, et al. Epidemiology of anterior cruciate ligament injuries in soccer. Am J Sports Med 1997;25:341-5.

34 Delfico A, Garrett W. Mechanisms of injury of the ACL in soccer players. Clin Sports Med 1998;17:779-85.

35 Heidt RS Jr, Sweeterman LM, Carlonas RL, et al. Avoidance of soccer injuries with preseason conditioning. Am J Sports Med 2000;28:659-62.

36 Hewett TE, Lindenfeld TN, Riccobene JV, et al. The effect of neuromuscular training on the incidence of knee injury in female athletes. A prospective study [comment]. Am J Sports Med 1999;27:699-706.

37 Junge A, Dvorak J, Chomiak J, et al. Medical history and physical findings in football players of different ages and skill levels. Am J Sports Med 2000;28:S16-21.

38 Junge A, Rosch D, Peterson L, et al. Prevention of soccer injuries: a prospective intervention study in youth amateur players. Am J Sports Med 2002;30:652-9.

39 Ekstrand J, Gillquist J, Liljedahl S. Prevention of soccer injuries. Am J Sports Med 1983;11:116-20.

\section{COMMENTARY}

This original article provides some valuable data on the incidence of injury in professional female soccer players and raises some interesting arguments regarding gender differences and the influence that professionalism has had on the development of the sport. The difference in injury rates may well reflect the differing levels of intensity between males and females at the elite end of the sport. However, there may also be some interesting lessons to be learnt by the male soccer population from the physical and mental preparation of their female counterparts to assist in reducing the risk of injury.

UK Sport, 40 Bernard Street, London WCIN 1ST, UK; scott.drawer@uksport.gov.uk

\section{ELECTRONIC PAGES}

\section{Online original articles}

$\mathrm{T}$ e following electronic only articles are published in conjunction with this issue of BJSM (see also pages 189 and 211)

\section{The repeatability and criterion related validity of the $20 \mathrm{~m}$ multistage fitness test as a predictor of maximal oxygen uptake in active young men}

\section{S-M Cooper, J S Baker, R J Tong, et al}

Objective: To investigate the repeatability and criterion related validity of the $20 \mathrm{~m}$ multistage fitness test (MFT) for predicting maximal oxygen uptake (Vo2max) in active young men.

Methods: Data were gathered from two phases using 30 subjects $(\mathrm{x} \pm \mathrm{s}$; age $=21.8 \pm 3.6$ years, mass $=76.9 \pm 10.7 \mathrm{~kg}$, stature $=1.76 \pm 0.05 \mathrm{~m})$. MFT repeatability was investigated in phase 1 where 21 subjects performed the test twice. The MFT criterion validity to predict $\mathrm{Vo}_{2 \max }$ was investigated in phase 2 where 30 subjects performed a continuous incremental laboratory test to volitional exhaustion to determine $\mathrm{Vo}_{2 \max }$ and the MFT.

Results: Phase 1 showed non-significant bias between the two applications of the MFT $\left(\bar{x}_{\text {diff }} \pm \mathrm{s}_{\text {diff }}=-0.4 \pm\right.$ $1.4 \mathrm{ml} \mathrm{kg}^{-1} \min ^{-1} ; \mathrm{t}=-1.37, \mathrm{p}=0.190$ ) with $95 \%$ limits of agreement (LoA) $\pm 2.7 \mathrm{ml} \mathrm{kg}^{-1} \mathrm{~min}^{-1}$ and heteroscedasticity $0.223(p=0.330)$. Log transformation of these data reduced heteroscedasticity to $0.056(\mathrm{p}=0.808)$ with bias $-0.007 \pm 0.025(\mathrm{t}=-1.35, \mathrm{p}=0.190)$ and $\mathrm{LoA} \pm 0.049$. Antilogs gave a mean bias on the ratio scale of 0.993 and random error (ratio limits) $\times / \div 1.050$. Phase 2 showed that the MFT significantly underpredicted $\mathrm{Vo}_{2 \max }\left(\overline{\mathrm{x}}_{\text {diff }} \pm\right.$ $\left.\mathrm{s}_{\text {diff }}=1.8 \pm 3.2 \mathrm{ml} \mathrm{kg}^{-1} \mathrm{~min}^{-1} ; \mathrm{t}=3.10, \quad \mathrm{p}=0.004\right) . \quad$ LoA were $\pm 6.3 \mathrm{ml} \mathrm{kg}^{-1} \mathrm{~min}^{-1}$ and heteroscedasticity 0.084 $(\mathrm{p}=0.658)$. Log transformation reduced heteroscedasticity to $-0.045(\mathrm{p}=0.814)$ with $\operatorname{LoA} \pm 0.110$. The significant systematic bias was not eliminated $\left(\bar{x}_{\text {diff }} \pm s_{\text {diff }}=0.033 \pm\right.$ $0.056 ; \mathrm{t}=3.20, \mathrm{p}=0.003)$. Antilogs gave a mean bias of 1.034 with random error $\times / \div 1.116$.

Conclusions: These findings lend support to previous investigations of the MFT by identifying that in the population assessed it provides results that are repeatable but it routinely underestimates $\mathrm{Vo}_{2 \max }$ when compared to laboratory determinations. Unlike previous findings, however, these results show that when applying an arguably more appropriate analysis method, the MFT does not provide valid predictions of $\mathrm{Vo}_{2 \max }$.

(Br J Sports Med 2005;39:e19) http://bjsm.bmjjournals.com/ cgi/content/full/39/1/e19

\section{Motivation and satisfaction among polyclinic volunteers at the 2002 Winter Olympic and Paralympic Games \\ J C Reeser, R L Berg, D Rhea, et al}

Background: The Olympic and Paralympic Games rely heavily on volunteers to provide many essential services, including medical care of athletes.

Objective: This preliminary investigation sought to characterise the motivational influences and factors responsible for the satisfaction of Olympic and Paralympic healthcare volunteers.

Methods: The 2002 Winter Games polyclinic healthcare volunteers were asked to complete a questionnaire designed to elicit information about their motives for volunteering and the factors that contributed to their satisfaction with their volunteer experience.

Results: There was no significant difference in the motivation or satisfaction summary scores based on event worked. There was a strong positive correlation between motivation and satisfaction. Physician respondents had a lower mean motivation score than did non-physician volunteers.

Conclusions: There were no significant motivational differences between Olympic and Paralympic volunteers, but there were several differences noted between physician and nonphysician volunteers. The 2002 polyclinic volunteers appear to have been motivated by a complex process best described as "enlightened self interest," and all were generally well satisfied with their experience. These results may assist organisers of future Games in selecting appropriately motivated volunteer personnel and creating rewarding work environments for them.

(Br J Sports Med 2005;39:e20) http://bjsm.bmjjournals.com/ cgi/content/full/39/1/e20 